Proc. Nat. Acad. Sci. USA

Vol. 71, No. 2, pp. 568-572, February 1974

\title{
Beginnings of Village-Farming Communities in Southeastern Turkey-1972
}

(Near Eastern excavations/plant and animal domestication/perennial settlements/early architecture)

\author{
ROBERT J. BRAIDWOOD*, HALET ÇAMBEL $\dagger$, BARBARA LAWRENCE $\ddagger$ CHARLES L. REDMAN§, \\ AND ROBERT B. STEWART ${ }^{\pi}$
}

* Oriental Institute, University of Chicago, Chicago, Illinois, 60637; † Prehistory Section, Istanbul University, Istanbul, Turkey;
$\ddagger$ Museum of Comparative Zoology, Harvard University, Cambridge, Massachusetts, 02138; $₹$ Department of Anthropology,
University of California, Berkeley, Calif., 94720; and I Department of Biology, Sam Houston State University, Huntsville, Texas, 77340

Contributed by Robert J. Braidwood, October 1, 1973

\begin{abstract}
The mound known as Cayönü Tepesi $\left(38^{\circ}\right.$ $16^{\prime} \mathrm{N} ; 3^{\circ} 43^{\prime} \mathrm{E}$ ) in southeastern Turkey is one of the increasing number of early village sites which, since World War II, have been excavated archeologically in greater southwestern Asia. The evidence recovered in the autumn 1972 campaign of the Joint Istanbul-Chicago Prehistoric Project is briefly described, with particular attention to Cayönü's architectural remains, which are most remarkable, considering the site's date of about 7000 B.C. There was evidence of domesticated food plants from the beginning but animal domesticates were not present (save the dog) until later in the major prehistoric phase of occupation.
\end{abstract}

The Joint Istanbul University-Chicago Oriental Institute Prehistoric Project continued its excavations in southeastern Turkey in the autumn of 1972. Throughout this fourth digging season, we concentrated on the mound called Cayönü, the site of an early village-farming community of about 7000 B.C. (1). Indeed our project's major research focus has long been the recovery and interpretation of evidence of the cultural and paleoenvironmental conditions within which effective food production was achieved in southwestern Asia (2). Without this achievement, mankind's earliest experiment with life in literate urban societies (which subsequently followed on the alluvial plain of southern Mesopotamia) could not have taken place.

By the end of our 1972 field season, with deepened older trenches and in newer operations (Fig. 1), slightly over $5 \%$ of the total three-hectare mound area of Çayönü had been exposed (at least in the upper levels). This is a gratifyingly impressive exposure in proportion to overall site size, as prehistoric excavations go. Nevertheless, the increased yield of evidence which came with this larger exposure makes us now realize that some of our earlier generalizations and interpretations were overly simplistic.

An example of this, which followed our 1970 season, was our assumption of a five-part stratigraphic succession in the major prehistoric occupation of Cayönü (3). The expanded 1972 exposures indicate that these five "phases" (which we shall henceforth refer to as sub-phases of the major prehistoric phase of occupation) were in fact an apparent succession of architectural plan types. In no case, however, have we yet encountered this apparent succession in one complete stratigraphically conformable series, all superimposed in one single exposure. There is also, now, a hint of still another plan type, but we have no proof as yet that the major prehistoric phase was made up of six such sub-phases over the whole mound's area. We do feel assured that the sequential order we suggest for the sub-phases is essentially correct. This sequence runs (from earliest to latest): (a) basal pits, (b) curved wall, (c) grill plan, $(d)$ broad-pavement plan, $(e)$ cell plan [ex "burnedbrick phase"]" and ( $f$ ) large-room plan. Nevertheless, since these were not all exposed in sequential stratigraphic order in one single trench, but in different trenches and at different depths, the exact correlations are yet to be worked out by interlinking the trenches. It is-for example-possible that the basal pits may have been due to outdoor activity adjacent to the curved-wall or grill-plan buildings and also possible that one or another of the broad-pavement buildings may have been continued in use during the cell-plan sub-phase. Hence we are increasingly reluctant to number the sub-phases consecutively.

There do appear to have been levels of rebuilding or renovation within at least the basal-pit, grill-plan, cell-plan, and large-room-plan sub-phases. These levels clearly lie in proper stratigraphic order. A better understanding of the exact stratigraphic nature of the prehistoric occupation remains one of our goals for subsequent work. Clearly, however, the stratification of Çayönü was not one of layer-cake regularity.

Save for the occurrence of simple artifacts of hammered native copper, the impressive element of the Çayönü inventory is its architecture or-strictly speaking-the stone foundations for its buildings. The earliest well-exposed example of these is of the grill-plan type (Fig. 2), of each five separate instances have so far been encountered, each with at least one superimposed rebuilding. All have the same approximate orientation and three appear to have had enclosed pavements on their southern side. We continue to assume that the "grills"-joist-like lines of stone foundations-were probably spanned by saplings, brush, reeds, and clay, or by flat stones and clay, to provide floors with some ventilation space below them. The largest of these foundations, a portion of which was first exposed in our 1964 field season, was finally cleared in 1972.

"In our 1970 description (1), Figs. 1 and 2 are of the grill plan, Fig. 6 of the broad-pavement plan, Fig. 3 of the cell plan, and Fig. 5 of the large-room plan sub-phases. It follows also that in shifting from the term "phase" to "sub-phase" for each apparent subdivision of the major prehistoric occupation, we now refer to all of this latter as Phase I and to the restricted traces of later protohistoric and historic horizons on Cayönü (ref. 1, p. 1236) as Phases II and III, respectively. 


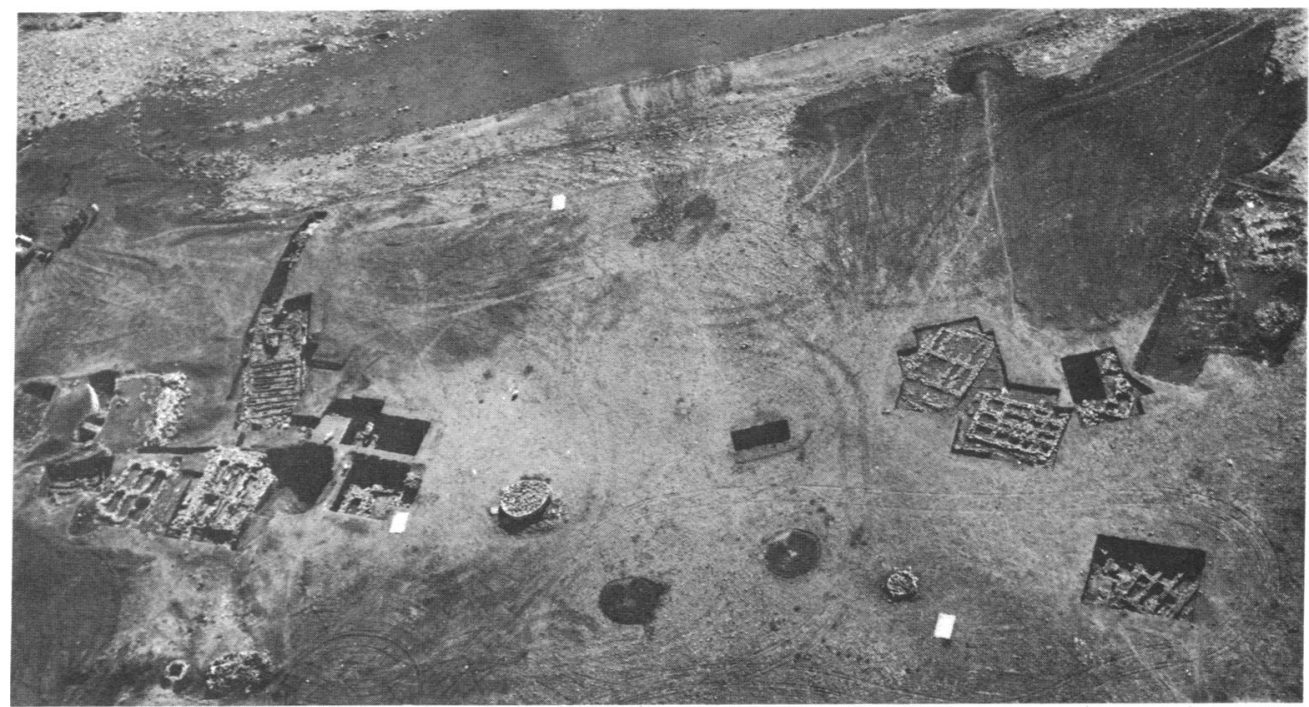

FIg. 1. Air view (looking south) of the area of excavations on Çayönü, with semi-refilled exposures made in previous field seasons showing on the extreme right and left. The distance between the two lower white markers is $50 \mathrm{~m}$.

Our broadest exposures in the 1972 season were of the cellplan foundations, of which six examples have now been cleared. Their stone foundation lines formed relatively small cell-like or bin-like units numbering either six or eight. These units vary in size, and the foundation wall lines have been found preserved one or two stones high or as much as ten stones high (over $70 \mathrm{~cm}$ ). It is not certain whether these cells functioned as rooms, storage spaces, or simply as air spaces (similar to the shallower air spaces we suggest for the grill buildings). If storage or air spaces were the case, then a normal living floor must have been supported by the foundation walls we recovered. In the three best-preserved structures, openings in the interior stone foundation wall lines have been found (Fig. 3), and these suggest crawlways or passageways between the cell-like rooms (no exterior openings have been noted). In the other three relatively complete foundations, the cell size appears to be absolutely too small to suggest rooms proper, and hence in these situations the storage- or airspace interpretation is most reasonable. In three well-preserved structures of this cell-plan type, what seems to have been an accidental fire has led to very fine preservation of the foundations of portions of the mud brick walls of the superstructures, and of much of the artifactual content. In two of the buildings, large quantities of ground stone and antler tools have been found, although if they fell from a living floor above as the building burned, they were not in situ in a strict "activity cluster" sense when we found them (ref. 1, Fig. 4). Four of the cell buildings, all of which were oriented roughly north-south, have some sort of enclosure or shelter on their northern end. In two of these cell buildings, groups of three human skeletons have been found in the northwestern cell (Fig. 4).

Although pertinent horizontal levels were cleared, the 1972 season's exposures did not yield further architectural informa-

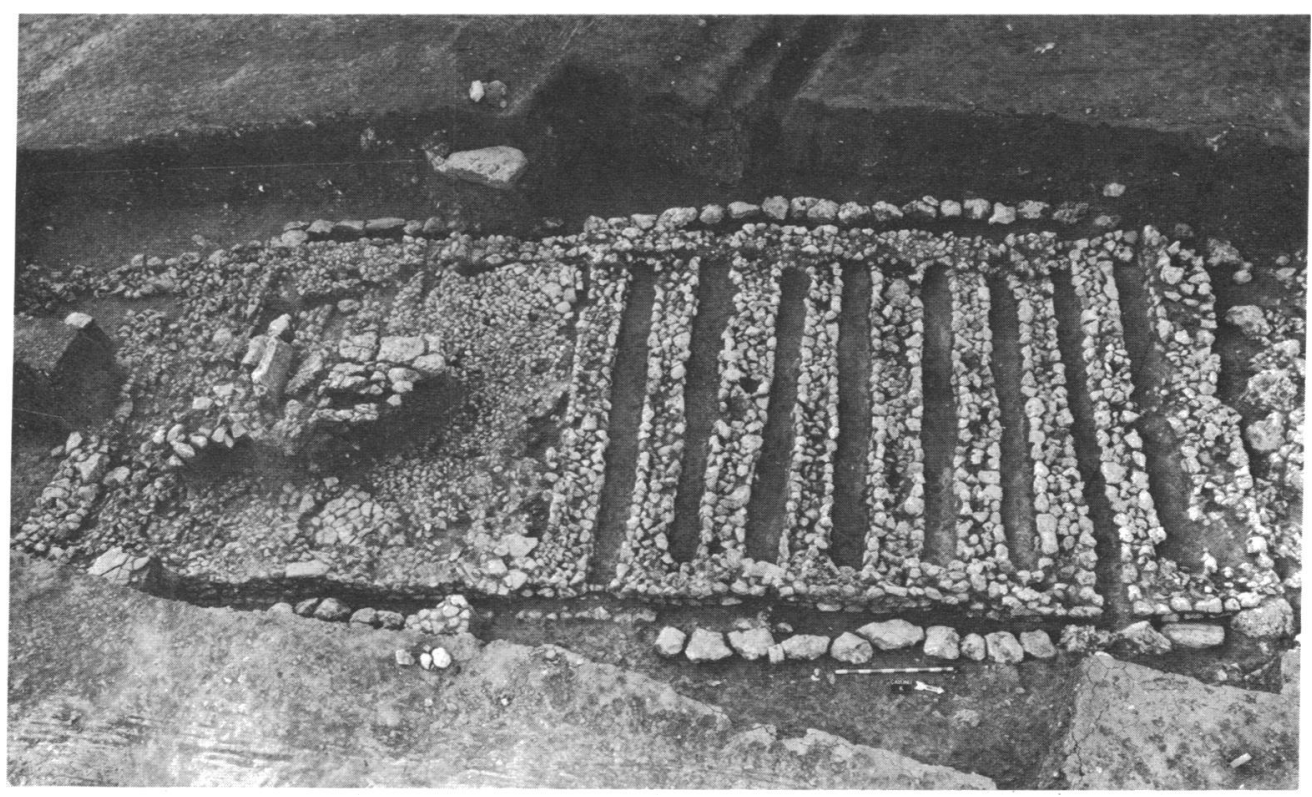

Fig. 2. A Çayönü grill-type-plan foundation. The large high stones, left center, are of a subsequent sub-phase. A one-meter scale lies in the right foreground. 


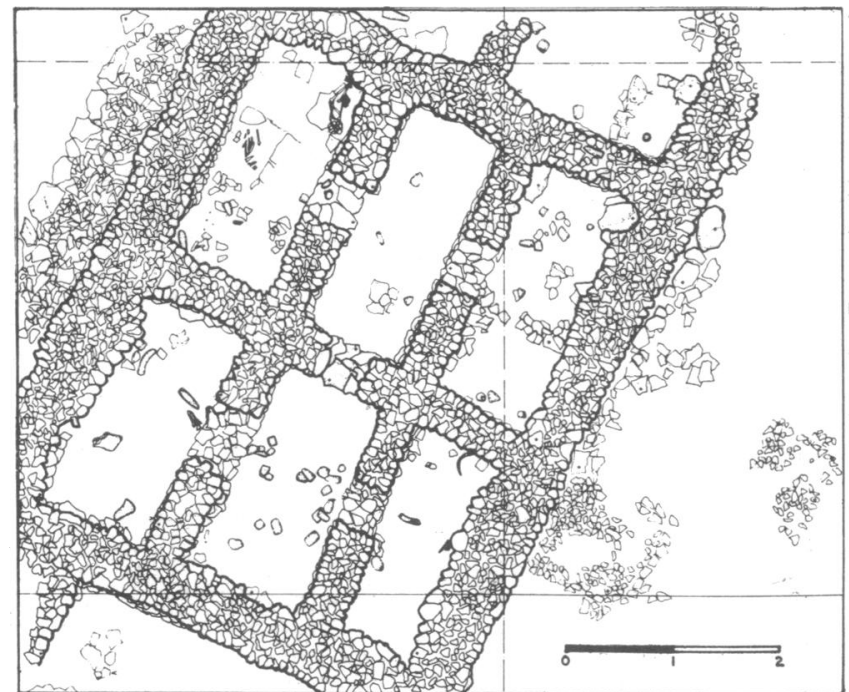

Fig. 3. A cell-type foundation plan showing the positions of larger artifacts, a burial, and the thresholds of interior openings between the cells. Scale is calibrated in meters.

tion on the large-room or the broad-pavement plan types. The possibly new plan type, with a roughly curved wall, was encountered as the season ended, only very partially exposed, and thus remains unfinished business. The basal pits and trash immediately above virgin soil were again tapped in two tests. While important otherwise, their yield was not architectural.

Sophisticated as they seem for their time range, the grillplan, cell-plan, and large-room-plan types remain conceivable as foundations for domestic structures. The broad-pavementplan type, however, especially in the instance of the terrazzo- floored structure of the 1970 field season, (ref. 1, Fig. 6) will not let us side-step considerations of buildings of some more specialized function. We are not yet ready to venture an opinion on what this function may have been.

As to additions to the small object inventory by our 1972 excavations, over 35,000 items in chipped flint and obsidian were given preliminary analysis. More copper fragments appeared, although in modest quantity, and the yield in clay figurines still remains lower than from contemporary sites along the Zagros flanks region. Most remarkable was a

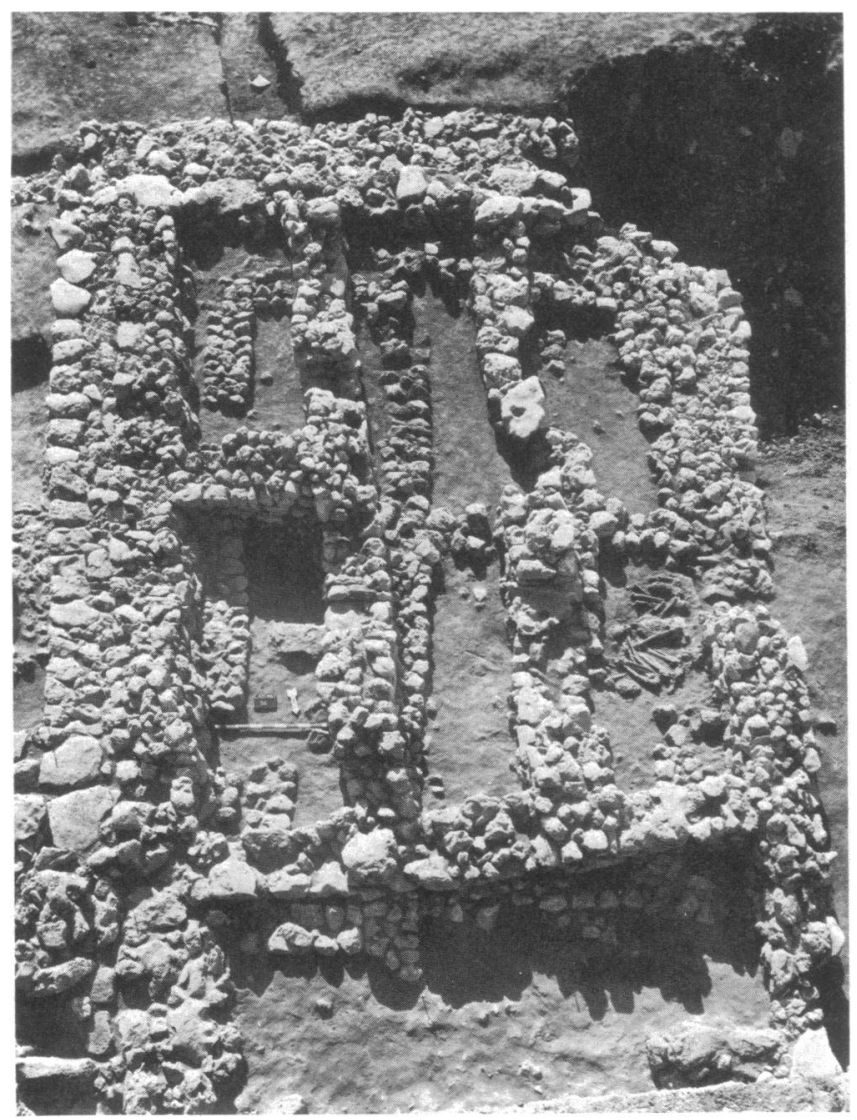

Fig. 4. An original cell-type foundation plan (lower stones) and a renovation of the same plan (upper stones), with a burial group in the lower right-hand cell 
rather leonine human (?) head. There were more substantial additions to the inventory in the ground stone and worked bone tool categories. Final analysis of the Cayönü inventory is in process.

Gathering data on the subsistence resources of the inhabitants of Cayönü, especially data that bear on the development of effective domestication of plants and animals, is of central importance to our expedition. With regard to the fauna, the 1972 season provided a more solid base for our earlier conclusions, and confirmed trends which previously had only been suggested. The total evidence, from the combined excavations of all four seasons, is of a shift from dependence on the big wild-game animals of the area, aurochs and red deer, to the use of domestic sheep and goats. In the earlier levels, up to and including those of the grill plan, aurochs bones were slightly more abundant than those of deer, and the two together were approximately twice as numerous as were sheep and goat bones combined. In the later levels, the situation was reversed with combined sheep and goat bones about 13 times as numerous as those of aurochs and red deer together. The picture is essentially the same, whether the comparison is based on the relative abundance of species or on the number of indentifiable bone fragments.

Given the present evidence and our understanding of the sequence at Cayönü, such a shift in the principal food animals is by itself a strong indication of domestication by the latest (and perhaps by the next-to-latest) sub-phase. This proposition for animal domestication in the later levels is reinforced by the slightly smaller average size of the sheep and goats, together with certain changes in their body proportions. In addition, the limited number of cranial fragments of sheep include three that are hornless, and for both sheep and goats the percentage of young animals is higher in these later levels.

However confident we may be of the case for domestication by the uppermost sub-phase, precisely what took place just before this appearance of domesticates is not clear. In the central areas of the mound, bone is scarce in the levels immediately preceeding those of the final sub-phase. In the adjacent areas examined, the uppermost levels lacked the largeroom sub-phase, and foundations of the cell-plan type were the first architectural traces encountered. Here, aurochs and deer bones were more numerous than sheep and goat bones, although with goat more abundant than sheep. As present evidence stands, it would seem that the time span in which the change was made from hunting to herding as a primary way of life at Cayönü was puzzlingly short, particularly as it apparently also involved a shift in emphasis from goat to sheep. More material is needed from the time-span immediately following the grill-plan sub-phase for a really reliable evaluation. At the moment, what is of particular interest is the apparent lack of a gradual transition between typically wild sheep and the domestic form.

Pigs were abundant throughout. There is some evidence that they were in part domestic by the later levels, but this question needs further study. One interesting faunal find was a group of four relatively complete lower jaws of large pigs, buried together in the southeastern cell of one of the cellplan foundations. Domestic dogs, though scarce, were present at least as early as the grill-plan buildings and probably from the beginning of Cayönü's occupation.

The 1972 season has expanded the known inventory of plants at Cayönü, as reported by Van Zeist from the 1970 excavations (4), to include grape, Rubus sp. (raspberry?) and several weed species. Van Zeist's findings have been confirmed or expanded in their critical aspects. Our major 1972 depth test (unit HA) encountered virgin soil below level 26 , and this level yielded cultivated einkorn wheat but its emmer wheat was morphologically wild. However, in the two succeeding levels (25 and 24, also of the basal-pits sub-phase), evidence of cultivated emmer appeared. Hence, insofar as unit HA can be considered as representing all of the major prehistoric occupation at Cayönü, cultivated emmer along with cultivated einkorn was present from the earliest sub-phase.

Van Zeist has noted the absence of barley at Cayönü. The 1972 excavations confirm this most remarkable fact-only three kernels of wild barley were recovered from the several thousand seeds examined. Contrary to other prehistoric agriculturists, it is apparent that the people of Cayönü deliberately excluded barley from their diets throughout the major prehistoric phase of occupation.

Although only the basal-pit and cell-plan sub-phases were architecturally well manifested in it, the total depth of unit HA must represent much of the major prehistoric phase at Cayönü. The botanical yield is thus of considerable interest. The 26 levels in HA were counted consecutively from the surface downwards to virgin soil. The seed yields from these levels were compared on the basis of species, number, and proportion of seeds per bucket of soil excavated, with special reference to three food classes: oil seeds (for fats), cereals (for carbohydrates) and pulses (for proteins). We suggest the following groupings of levels by food class and quantity as they may relate to the probable depth zones of the architectural sub-phases**. The basal-pit sub-phase (in case it actually has an entity of its own and is not simply due to outdoor activity by the builders of the curved-wall and/or grill-plan structures) corresponds to the HA levels 26 through 23 . Both pulses and oil seeds showed a higher proportion in these levels than in the following grouping (levels 22-13), but there was little difference in the cereals between the two groupings. Along with emmer and einkorn, rye grass (Lolium sp.) was a major component. The group of levels from 22 through 13 is probably assignable to the grill-plan and broad-pavement-plan sub-phases. It is characterized by about equal proportions and quantities of the three seed components: oil seeds, pulses, and cereals. The grouping of levels from 12 to the surface in HA was marked by almost no oil seeds and by relatively fewer pulses and cereals than earlier. This grouping probably all belongs to the cell-plan sub-phase, as its uppermost levels demonstrably do. No trace of the large-room-type plan was encountered in unit HA, where the cell-plan foundation was the first thing to appear immediately under the surface.

One might be tempted to dismiss this diminishing supply of grains and pulses, as well as the absence of pistachio, the primary oil seed here, as due to poor preservation in the upper levels generally, were it not for the fine preservation of carbonized grain in an adjacent square at the same elevation and of the cell-plan subphase. Rather it seems that the general decline of traces of food plants, as well as the change between the lower groupings, indicates a real difference in dependency

** With only the basal-pit and the cell-type plans positively identifiable in operation HA, these suggestions can be no more than our best present guesses as to the probable correspondence between others of the HA levels and the other architectural sub-phases. 
sources. These differences can be correlated with the architectural sub-phases.

A further interesting characteristic of HA is noted when the animal resources, reported by Lawrence, are superimposed on a plotting of plant distribution; the result is an inverse correlation. Throughout the entire depth in unit HA, when the bone yield is high, the plant yield is low and vice versa. This is particularly striking with oil seeds versus bone. We believe this reflects a change in diet, perhaps caused by environmental change. It is hoped that our pollen analysis of soil from Cayönü will give evidence on this question.

With increasing exposure and a larger yield of evidence, our task of culture-historical generalization and interpretation becomes more complicated. Sub-phase by sub-phase, common building orientations and plan types impress us; these did not remain static as time went on. Changes also occurred in the inventory of items of daily use and in the elements of subsistence, but our evidence is still too incomplete to allow us to sense the exact socio-cultural meanings of these changes. Perhaps this need not surprise us too much-the people of Cayönü may well have been just as perversely idiosyncratic as people still are. Nevertheless they were part of one of the great experiments in change in human history, and gaining understandings of it remains the overwhelming challenge.

We are particularly indebted to the authorities of the Turkish Antiquities Service, of the Vilayet of Diyarbakir and of the Turkish Air Force (whose flights provided us with air photos of the excavations), to our earlier staff participants (1) for further advice, and to Erin Waters, CISRO, Melbourne, for his analysis of the terrazzo pavement. As well as by grants from our two universities, our field operations were substantially supported by the National Science Foundation (GS 30365). Again we benefited through the participation of an enthusiastic and effective group of graduate students, from Turkey and from the United States as well as from France and Sweden. The American students were supported through a Ford Foundation Grant for graduate field training.

1. Braidwood, R. J., Çambel, H., Redman, C. L. \& Watson, P. J. (1971) Proc. Nat. Acad. Sci. USA 68, 1236-1240.

2. Braidwood, R. J. (1972) Proc. Amer. Phil. Soc. 116, 310-320; (1973) Paleorient 1, 7-10.

3. Braidwood, R. J., Çambel, H., Redman, C. L. \& Watson, P. J. (1971) Proc. Nat. Acad. Sci. USA 68, 1236-1240, also Redman, C. L. (1973) Amer. Antiquity 38, 61-79.

4. Van Zeist, W. (1972) Helinium 12, 3-19.

5. Redman, C. L. (1973) Amer. Antiquity 38, 61-79. 